\title{
Poliovirus tropism and attenuation are determined after internal ribosome entry
}

\author{
Steven E. Kauder and Vincent R. Racaniello \\ Department of Microbiology, Columbia University College of Physicians and Surgeons, New York, New York, USA.
}

\begin{abstract}
Poliovirus replication is limited to a few organs, including the brain and spinal cord. This restricted tropism may be a consequence of organ-specific differences in translation initiation by the poliovirus internal ribosome entry site (IRES). A C-to-U mutation at base 472 in the IRES of the Sabin type 3 poliovirus vaccine strain, known to attenuate neurovirulence, may further restrict tropism by eliminating viral replication in the CNS. To determine the relationship between IRES-mediated translation and poliovirus tropism, recombinant human adenoviruses were used to express bicistronic mRNAs in murine organs. The IRESs of poliovirus, the cardiotropic coxsackievirus B3 (CVB3), and the hepatotropic hepatitis C virus (HCV) mediate translation in many organs, including those that do not support viral replication. A translation defect associated with the Sabin type 3 IRES was observed in all organs examined. Poliovirus type 1 and recombinant polioviruses dependent on the IRES of CVB3 or HCV replicate in the CNS of mice and cause paralysis. Although the type 3 Sabin strain is an effective vaccine, polioviruses with a $U$ at base 472 of the IRES cause paralysis in newborn mice. Tropism of wild-type and vaccine strains of poliovirus is therefore determined after internal ribosome entry.
\end{abstract}

\section{Introduction}

The initiation of most eukaryotic protein synthesis is dependent on the recruitment of ribosomes to the mRNA $5^{\prime}$ end by the $5^{\prime}$ 7 -methylguanosine cap structure $(1,2)$. However, translation of some viral and cellular mRNAs is initiated when a cis-acting RNA sequence called an internal ribosome entry site (IRES) binds ribosomes in a 5' end- and cap-independent manner (3-7). The first IRES was identified within the $5^{\prime}$ untranslated region of the poliovirus RNA genome (8), which is an mRNA but lacks a $5^{\prime}$ cap structure $(9,10)$. Translation in eukaryotic cells may be regulated at the step of IRES-dependent initiation $(4,7)$.

It has been suggested that poliovirus tropism, defined as the organs where the virus replicates, is determined by cell type-specific differences in translation initiation by the poliovirus IRES (11-14). Poliovirus replication is limited to the brain and spinal cord, oropharyngeal and intestinal mucosa, tonsils, Peyer's patches, and cervical and mesenteric lymph nodes (15). The poliovirus receptor is not sufficient to determine poliovirus tropism, because this protein is produced in a broad range of animal tissues (16-18). The ability of poliovirus to replicate in different organs may be determined at a postentry step such as translation of the viral RNA. Cell proteins other than the canonical translation-initiation factors have been identified that influence IRES-mediated translation (19). Viral replication could be regulated by organ-specific synthesis, localization, or modification of these cell proteins. Recombinant polioviruses dependent on the IRES of human rhinovirus 2 or hepatitis $\mathrm{C}$ virus (HCV) do not accumulate or cause disease in the brain and spinal cord of mice $(12,13,20)$. These results have been interpreted as indicating that the IRESs of rhinovirus and $\mathrm{HCV}$ do not mediate translation initiation in the

Nonstandard abbreviations used: coxsackievirus B3 (CVB3); hepatitis C virus (HCV); internal ribosome entry site (IRES); passive lysis buffer (PLB); transgenic poliovirus receptor (TgPVR).

Conflict of interest: The authors have declared that no conflict of interest exists.

Citation for this article: J. Clin. Invest. 113:1743-1753 (2004).

doi:10.1172/JCI200421323. brain and spinal cord. However, there have been no direct measurements in organs of translation initiation dependent on the IRES of rhinovirus, poliovirus, or HCV.

Organ-specific IRES-mediated translation has also been hypothesized to account for the reduced neurovirulence of the Sabin live attenuated poliovirus vaccine strains. These vaccine strains infect the alimentary tract, producing immunity to infection but rarely causing paralysis (21). Genetic analysis has demonstrated that a point mutation within the IRES of all three poliovirus vaccine strains is a determinant of the attenuation phenotype (22-24). A mutation from $\mathrm{C}$ to $\mathrm{U}$ at nucleotide 472 in the IRES of poliovirus type 3 is sufficient to attenuate neurovirulence in primate and murine models $(23,25,26)$. Studies of IRES-mediated translation initiation have demonstrated that a change from $\mathrm{C}$ to $\mathrm{U}$ at nucleotide 472 causes a translation defect in vitro and in cultured cells of neuronal origin (27-29). It has been hypothesized that the translation defect caused by the $\mathrm{C} 472 \mathrm{U}$ mutation is specific to the brain and spinal cord and leads to a defect in viral replication in these organs $(11,27,30)$. This replication defect might explain the reduced neurovirulence of the oral poliovirus vaccine strains. However, it is not known whether mutations in the poliovirus IRES reduce translation in the brain and spinal cord but not in other organs.

Two experimental approaches were used to determine the relationship between IRES-mediated translation and poliovirus tropism. Using recombinant human adenoviruses to express bicistronic mRNAs in murine organs, the IRESs of poliovirus, coxsackievirus B3 (CVB3), and HCV were found to mediate translation in many organs, including those that do not support viral replication. A translation defect associated with the Sabin type 3 IRES was observed in all organs examined. In a mouse model of poliomyelitis, recombinant polioviruses dependent on the IRES of CVB3 or HCV replicate in the CNS and cause paralysis. Polioviruses with a $U$ at base 472 of the IRES cause paralysis in newborn mice. These findings demonstrate that tropism of wild-type and vaccine strains of poliovirus is determined after internal ribosome entry. 
A
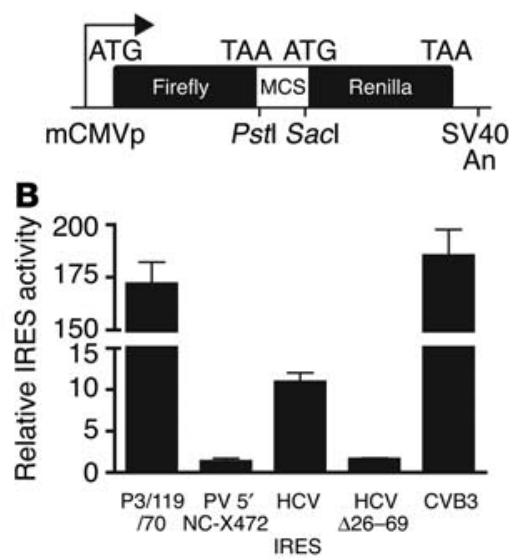

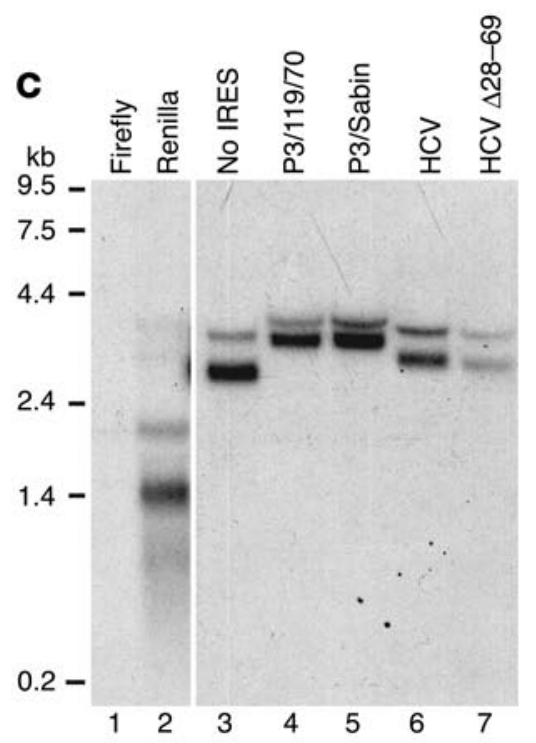

D

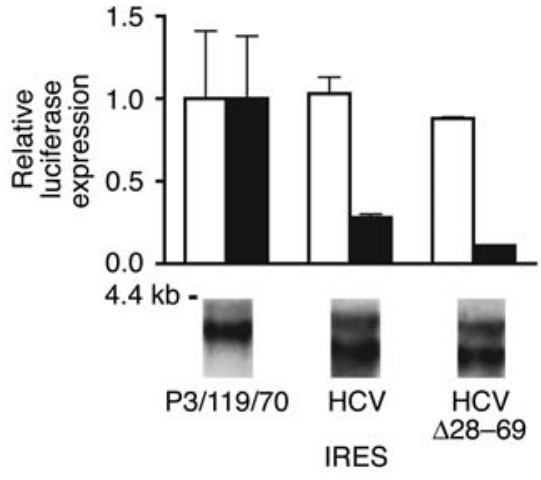

Figure 1

IRES-mediated translation in A549 cells infected with recombinant adenoviruses. (A) Schematic of bicistronic reporter DNA. The arrow indicates the transcription-initiation site of the murine cytomegalovirus immediate early promoter. Firefly luciferase and Renilla luciferase have independent translation initiation and termination codons. SV40 An, simian virus 40 polyadenylation signal. (B) IRES activity in cells infected with adenovirus encoding bicistronic mRNA. The $x$ axis indicates IRES encoded in the recombinant adenovirus. PV 5'NC-X472, poliovirus IRES with Xhol linker substitution at nucleotide 472; HCV $\triangle 28-69$, HCV IRES with deletion of nucleotides 28-69. (C) Northern blot hybridization of A549 cells. Cells were infected with recombinant adenoviruses indicated at the top. RNA size markers are given at left. Lane 1, monocistronic firefly luciferase; lane 2 , monocistronic Renilla luciferase; lane 3, bicistronic mRNA, no IRES; lane 4, bicistronic mRNA with P3/119/70 IRES; lane 5, bicistronic mRNA with P3/Sabin IRES; lane 6, bicistronic mRNA with HCV IRES; lane 7, bicistronic mRNA with HCV IRES lacking nucleotides 28-69. First two lanes are from the same gel as lanes 3-7 but were exposed for a longer period of time. (D) Luciferase expression in adenovirus-infected cells. Upper panel: Firefly luciferase (white bars) and Renilla luciferase expression (black bars). Luciferase was normalized to the P3/119/70 IRES value for each reporter protein, and also to the quantity of bicistronic mRNA determined by Northern blot hybridization. Lower panels: Representative Northern blot hybridizations of RNA from the same infected cells. IRES encoded by bicistronic mRNA is indicated at the bottom. Data points in $\mathbf{B}$ and $\mathbf{D}$, the results of separate experiments, are the mean of three infections, and error bars indicate SD.

\section{Results}

Expression of bicistronic $m R N A$ from recombinant human adenovirus. A system was developed to measure IRES activity in murine organs. Recombinant human adenovirus vectors were produced that express bicistronic mRNAs that encode two reporter proteins separated by an IRES (Figure 1A). These bicistronic mRNAs possess a $5^{\prime}$ cap structure, and translation of the first open reading frame occurs by $5^{\prime}$ end-dependent initiation. Efficient translation of the second open reading frame requires an IRES to mediate internal binding of ribosomes.

To demonstrate that an IRES-dependent mRNA can be translated when expressed from an adenovirus vector, A549 cells were infected with adenoviruses that encode bicistronic mRNAs with the IRES of poliovirus, HCV, or CVB3. Inclusion of the IRES within a bicistronic mRNA results in significantly higher levels of Renilla luciferase activity compared with a short, unstructured sequence (Figure 1B). These results agree with those of previous studies that showed that the inclusion of the IRES of poliovirus, $\mathrm{HCV}$, or CVB3 in an mRNA results in increased expression of the downstream reporter gene $(8,31,32)$. The effects of mutations previously shown to abrogate IRES-mediated translation were determined. Substitution of an XhoI linker for nucleotides 472-479 of the poliovirus IRES, or deletion of nucleotides 28-69 from the HCV IRES, has been shown to impair translation $(33,34)$, and these mutations reduce Renilla luciferase activity in adenovirus vector-infected cells (Figure 1B). These findings provide genetic evidence that Renilla luciferase activity observed in adenovirus vector-infected cells is a consequence of internal initiation.

To confirm that Renilla luciferase is present only in fulllength mRNAs, Northern blot hybridization of RNA from adenovirus vector-infected cells was performed (Figure 1C). No species smaller than the full-length bicistronic mRNA was detected in cells infected with these adenoviruses. These findings demonstrate that Renilla luciferase is translated by internal ribosome entry on full-length bicistronic mRNAs, and not by $5^{\prime}$ end-dependent translation of smaller RNAs produced by RNA degradation, splicing, or aberrant transcription. An additional RNA approximately 500 nucleotides larger than the bicistronic mRNA was also detected (Figure 1C). This RNA likely results from transcription termination at the adenovirus E1b polyadenylation signal 500 nucleotides downstream of the simian virus 40 polyadenylation signal (35).

Because IRES activity is based on standardization of Renilla to firefly activity, any effect of the IRES on translation of the upstream reporter protein would prevent a reliable quantitation of translation initiated by the IRES. To address this possibility, firefly and Renilla luciferase activities were measured in infected cells and normalized to the amount of bicistronic RNA as determined by Northern blot hybridization. Normalization compensates for differences in luciferase activity that result from variation in infection efficiency or transcription. The findings demonstrate that the IRES has no effect on firefly luciferase translation (Figure 1D). 


\section{A}
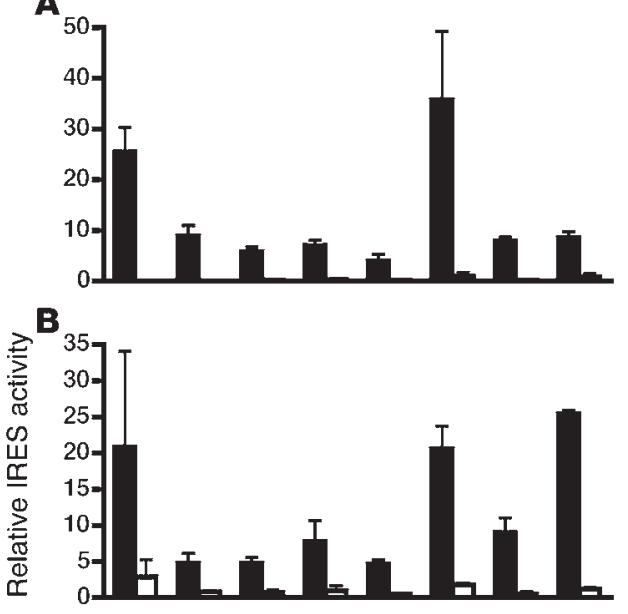

c

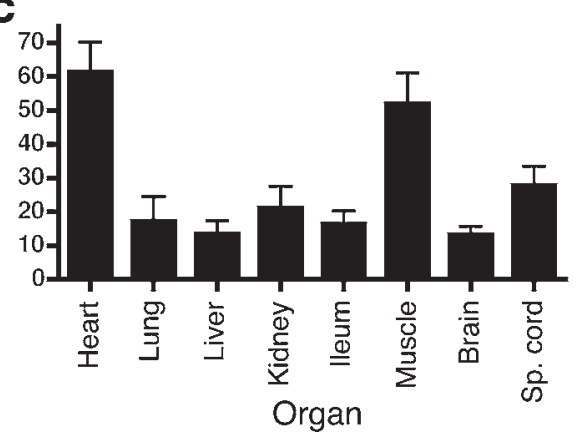

IRES-mediated initiation of translation in murine organs. In animals, IRES-mediated internal initiation of translation could be restricted to specific organs. To address this hypothesis, mice were infected with recombinant adenovirus vectors that encode bicistronic mRNAs. The IRES of poliovirus, HCV, and CVB3 is functional in all organs examined, including brain, spinal cord, skeletal muscle, heart, lung, liver, kidney, and ileum (Figure 2, A-C).

To provide genetic evidence that Renilla luciferase translation in mice is mediated by the viral IRES, the effect of mutations in the IRES was assessed. As was observed in cultured cells (Figure 1B), substitution of an $\mathrm{XhoI}$ linker for nucleotides $472-479$ of the poliovirus IRES, or deletion of nucleotides 28-69 from the HCV IRES, nearly eliminates IRES activity in mouse organs (Figure 2, A and B). No firefly or Renilla luciferase activity was detected when mice were infected with an adenovirus lacking the promoter necessary for production of bicistronic mRNA with the poliovirus IRES (data not shown). This result shows that translatable Renilla luciferase mRNAs are not produced from a promoter within the poliovirus IRES.

IRES activity should be independent of the quantity of infecting virus. When mice were inoculated with amounts of virus

\section{Figure 3}

Relationship between dose of recombinant adenovirus and IRES activity in mouse brain. (A) Firefly luciferase (squares) and Renilla luciferase (triangles) expression in mouse brain. (B) Activity of the poliovirus type $3119 / 70$ IRES in the mouse brain, normalized to activity at a dose of $10^{6}$ PFUs. The $x$ axis indicates adenovirus dose in $\log _{10}$ PFUs. Data points are the mean of five infections, and error bars indicate SD.

\section{Figure 2}

IRES-mediated translation in murine organs infected with recombinant adenoviruses. (A) Poliovirus type 3 119/70 IRES (black bars) and poliovirus type $15^{\prime}$ NC-X472 IRES (white bars). (B) HCV 1b IRES (black bars) and HCV 1a IRES with nucleotides 28-69 deleted (white bars). (C) CVB3 IRES. Data points are the mean of at least five mice, and error bars indicate SD.

ranging from $10^{6}$ to $10^{10}$ PFUs, levels of firefly luciferase and Renilla luciferase increased nearly 10,000 times (Figure 3A), but activity of the poliovirus IRES remained constant (Figure 3B). Therefore IRES activity in an organ is not affected by the quantity of infecting vector virus.

Does the IRES determine sites of viral replication and disease? Studied in isolation from the viral genome, the IRES of poliovirus, $\mathrm{HCV}$, or CVB3 mediates translation in many organs. In the genome, organ specificity of an IRES could be influenced by viral RNA sequences or proteins produced during viral replication. To address this possibility, the poliovirus IRES was substituted with the cognate sequence from viruses that infect different organs (Figure 4A). The IRES of human poliovirus type 1 was replaced with that of $\mathrm{HCV}$, which is hepatotropic (36), or with the IRES of CVB3, which causes myocarditis (37). These recombinant viruses were named P1/HCV and P1/CVB3. Single-step growth analysis of both recombinant viruses in HeLa cells reveals a defect in replication, comprising an early delay in virus production (Figure 4B). While the final yield of $\mathrm{P} 1 / \mathrm{CVB} 3$ approached that of poliovirus type 1 , the yield of $\mathrm{P} 1 / \mathrm{HCV}$ was significantly lower. Previous results have demonstrated that the poliovirus IRES contains determinants of viral RNA replication $(38,39)$. It is possible that exchange of the poliovirus IRES has removed cis-acting sequences important for RNA replication.

Virulence and tropism of recombinant viruses were determined in mice transgenic for the human poliovirus receptor gene (40). After intraperitoneal inoculation of adult transgenic poliovirus receptor (TgPVR) mice with poliovirus type 1, virus replicates to high titers in the brain and spinal cord (Figure 5A). In contrast, virus titers in the heart steadily decline after infection, and virus
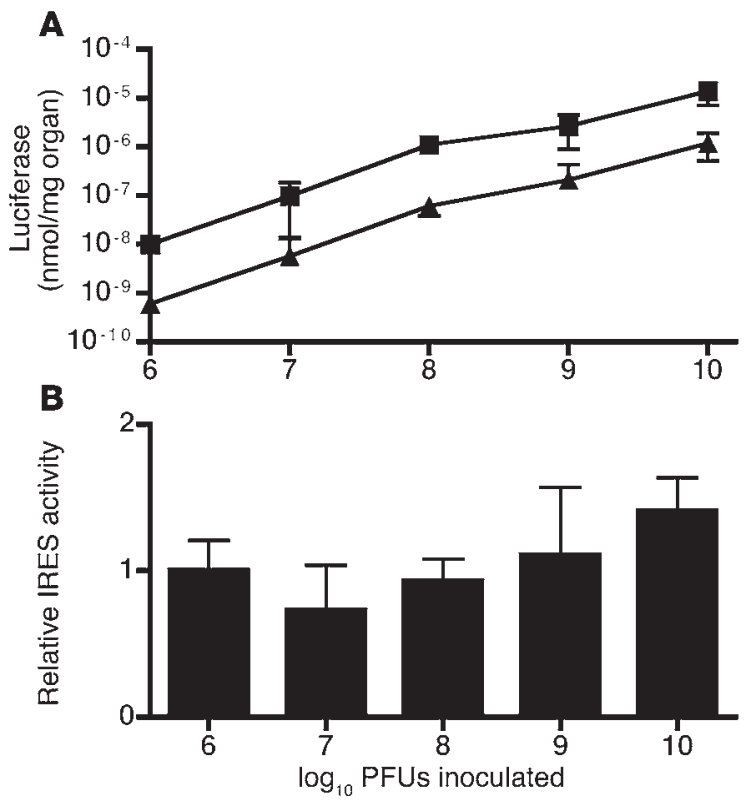

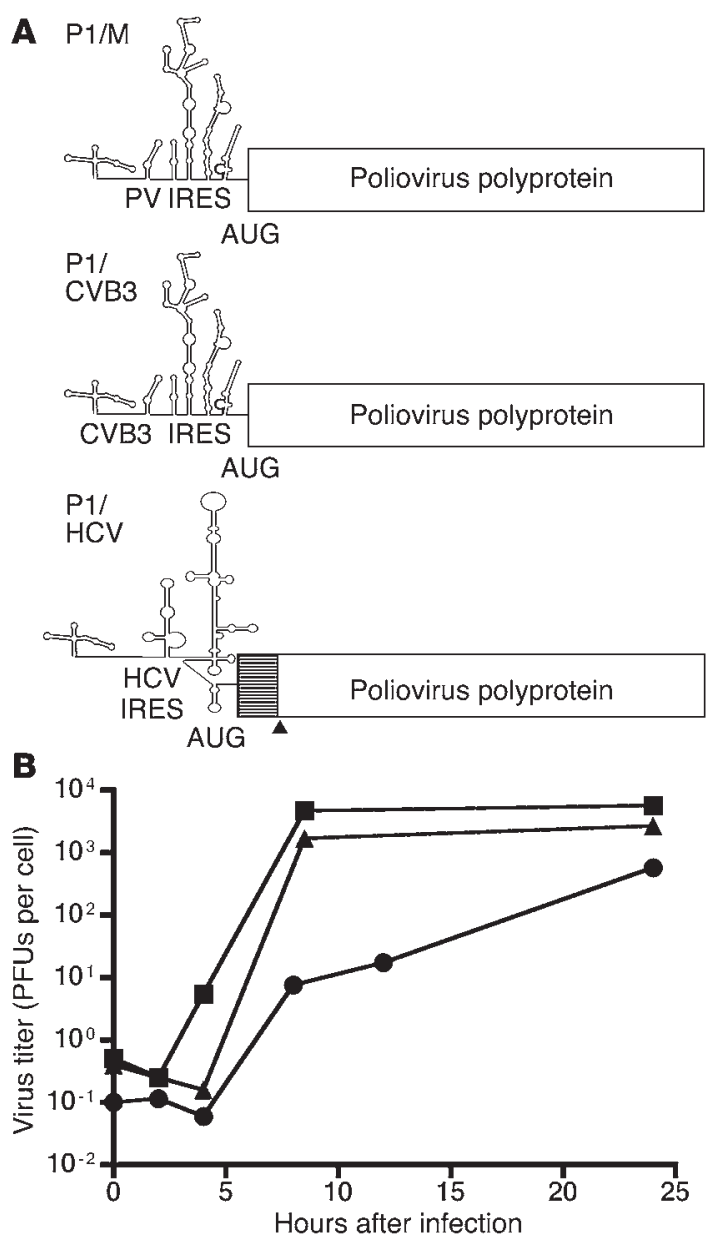

titers in the pancreas increase by day 3 and subsequently decline (Figure 5A). In newborn TgPVR mice, there is a large increase in virus titer in the brain and spinal cord, and a moderate increase in the liver (Figure 5C). Infection of adult and newborn TgPVR mice leads to flaccid limb paralysis and death (40). Viral replication and pathogenesis are not observed in nontransgenic mice (40).

To determine the effect of IRES replacement on poliovirus pathogenesis, TgPVR mice were infected with recombinant viruses. P1/CVB3 replicates and causes disease in adult TgPVR mice (Figure 5, B and E). Virus titers in the brain and spinal cord increase 10,000-fold during the course of infection (Figure 5B). Some infected mice develop flaccid hind-limb paralysis or die (Figure 5E). CVB3 replication and pathogenesis occur in heart and pancreas of adult mice $(41,42)$, yet the pattern of $\mathrm{P} 1 / \mathrm{CVB} 3$ replication in these organs is unchanged from that of poliovirus type 1 (Figure 5, A and B). When adult TgPVR mice were inoculated with $\mathrm{P} 1 / \mathrm{HCV}$, viral replication and disease did not occur (data not shown). However, $\mathrm{P} 1 / \mathrm{HCV}$ replicates and causes disease in newborn TgPVR mice (Figure 5, D and E). Virus titers in the brain and spinal cord increase 500- and 1,000-fold, respectively, during the course of infection (Figure 5D). Some infected mice develop flaccid hind-limb paralysis or die (Figure 5E). HCV replicates and causes disease in primate liver, yet in TgPVR mice P1/HCV is cleared from this organ (Figure 5D). Virulence of virus recovered from paralyzed newborn TgPVR mice was unchanged in newborn and adult mice

\section{Figure 4}

Replication and virulence of recombinant poliovirus strains. (A) Genome structure of poliovirus type 1 strain Mahoney, recombinant strain P1/CVB3, and recombinant strain $\mathrm{P} 1 / \mathrm{HCV}$. IRES, predicted AUG initiation codons, and poliovirus polyprotein (open box) are indicated. Translation of $\mathrm{P} 1 / \mathrm{HCV}$ is predicted to initiate at the HCV AUG initiation codon, which is followed by 369 nucleotides of HCV polyprotein sequence (lined box). Sequence encoding the recognition site for poliovirus protease $2 A^{\text {pro }}$ (triangle) separates HCV sequence and nucleotide 745 of the poliovirus genome. (B) Single-step replication analysis in HeLa cells of poliovirus type 1 strain Mahoney (squares), P1/CVB3 (triangles), and P1/HCV (circles). Data points are the mean of two infections.

(data not shown). Replication of poliovirus type 1 in the brain and spinal cord of mice and development of paralytic disease are dependent on the human poliovirus receptor (40). P1/HCV and $\mathrm{P} 1 / \mathrm{CVB} 3$ are cleared from the brain and spinal cord of nontransgenic mice (Figure 5, B and D), and paralysis does not occur (Figure 5E and data not shown). The human poliovirus receptor is required for paralytic disease and increases in viral titers after inoculation, further evidence that $\mathrm{P} 1 / \mathrm{HCV}$ and $\mathrm{P} 1 / \mathrm{CVB} 3$ replicate in the murine brain and spinal cord.

Do mutations in the IRES of poliovirus vaccine strains have an organspecific effect on translation? It has been suggested that neuroattenuation caused by a C472U mutation in the IRES of poliovirus vaccine strains is a consequence of reduced translation of poliovirus RNA in the brain and spinal cord. The effect of the C472U mutation on translation in murine organs was therefore determined. Recombinant adenoviruses were produced that encode bicistronic mRNAs with the poliovirus type 3 IRES and either a $C$ or a $U$ at nucleotide 472. The C472U mutation decreases IRES-dependent translation in continuous cell lines of both neuronal and nonneuronal origin (Figure 6A). No species smaller than the fulllength bicistronic mRNA was detected in cells infected with either adenovirus (Figure 6A). The C472U mutation also decreases IRESdependent translation in murine brain, spinal cord, heart, lung, liver, kidney, ileum, and muscle (Figure 6B).

It has previously been shown that poliovirus strains with the C472U mutation are cleared from the brain and spinal cord of adult mice and fail to cause paralysis (26). To determine whether virus strains with the $\mathrm{C} 472 \mathrm{U}$ mutation have lost the ability to replicate within the murine brain and spinal cord, newborn TgPVR mice were infected with polioviruses with either $\mathrm{C}$ or $\mathrm{U}$ at nucleotide 472 . The neurovirulence of these viruses was then determined as a measure of their ability to replicate in the murine brain and spinal cord (Table 1). Poliovirus strain PRV7.3, with U at nucleotide 472 , is nearly as neurovirulent in newborn mice as virus strain PRV8.4, which is identical except for a $\mathrm{C}$ at nucleotide 472. In contrast, the neurovirulence of virus strain PRV7.3 is attenuated in adult TgPVR mice. The poliovirus type 3 vaccine strain P3/Sabin, which is neuroattenuated in adult TgPVR mice, is virulent in newborn TgPVR mice. As expected, virus strains P3/119/70 and PRV8.4, both with C at nucleotide 472, are neurovirulent in adult TgPVR mice, and virus strain P3/119/70 is highly neurovirulent in newborn mice. These findings demonstrate that the neuroattenuating mutation at nucleotide 472 of the poliovirus genome does not eliminate viral replication in the murine brain and spinal cord.

Viruses with a reversion of the $\mathrm{C} 472 \mathrm{U}$ mutation may accumulate during replication of PRV7.3 and P3/Sabin in cell culture 

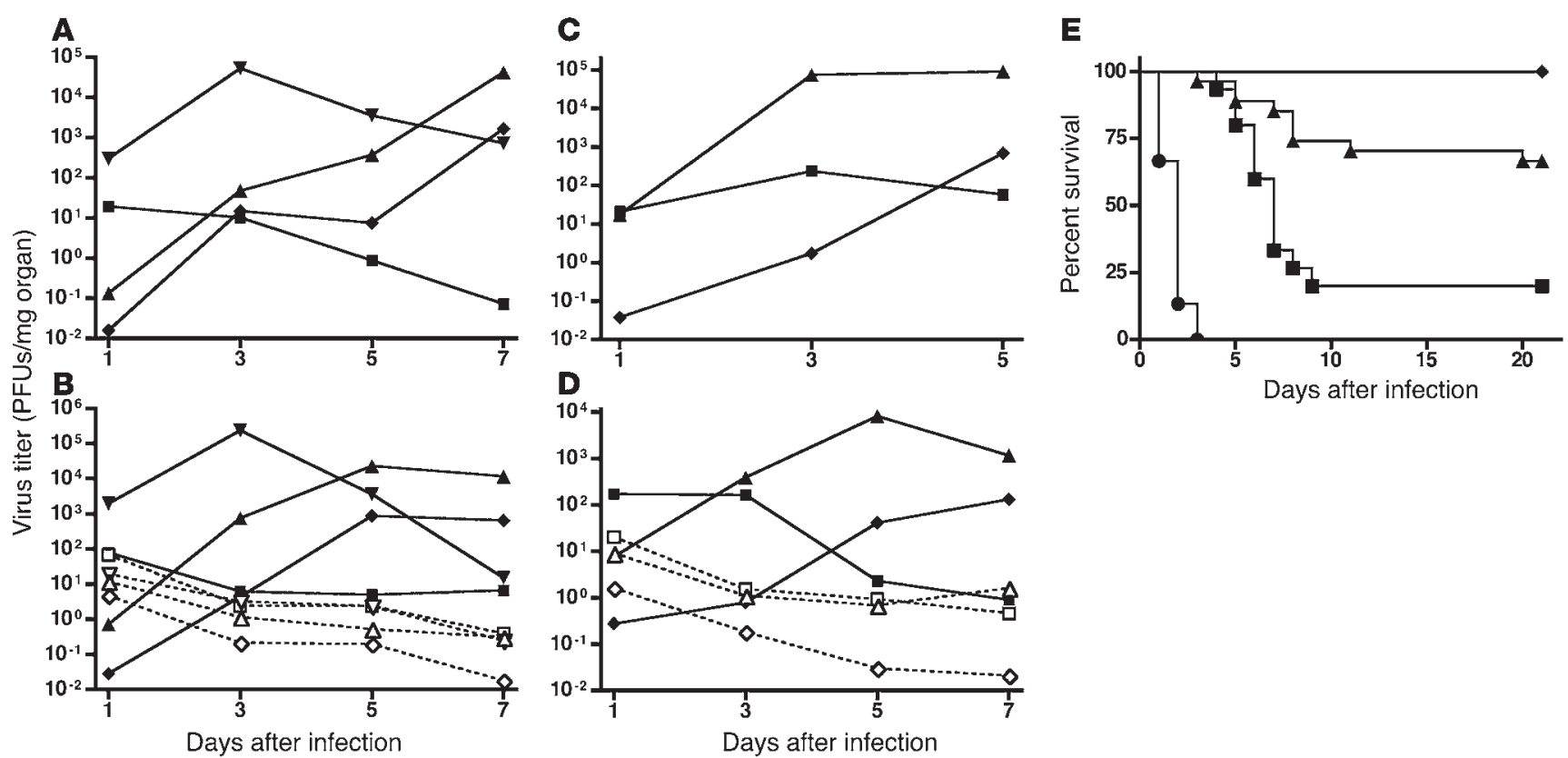

Figure 5

Poliovirus infection of mice. (A-D) Poliovirus replication in murine organs. The $y$ axis indicates virus titer at the indicated days after infection. (A) Virus titers in pancreas (filled inverted triangles), spinal cord (filled triangles), brain (filled diamonds), and heart (filled squares) of adult TgPVR mice infected with poliovirus. (B) Virus titers in spinal cord (filled and open triangles), brain (filled and open diamonds), pancreas (filled inverted and open inverted triangles), and heart (filled and open squares) of adult TgPVR (solid lines) and nontransgenic (dashed lines) mice infected with P1/CVB3. (C) Virus titers in spinal cord (filled triangles), brain (filled diamonds), and liver (filled squares) of newborn TgPVR mice infected with poliovirus. (D) Virus titers in spinal cord (filled and open triangles), brain (filled and open diamonds), and liver (filled and open squares) of newborn TgPVR (solid lines) or nontransgenic (dashed lines) mice infected with P1/HCV. Data points are the geometric mean titer in organs from at least three mice. (E) Virulence of recombinant poliovirus strains. The $y$ axis indicates the percentage of surviving mice at different times after infection. TgPVR mice were infected with $10^{7}$ PFUs P1/CVB3 (squares), $2 \times 10^{6}$ PFUs P1/HCV (triangles), or $10^{9}$ PFUs P1/HCV (circles); nontransgenic mice were infected with $2 \times 10^{6} \mathrm{PFUs} \mathrm{P} 1 / \mathrm{HCV}$ (diamonds).

or in animals $(23,43)$. The fraction of viral revertants can be readily determined by restriction enzyme cleavage of a DNA copy of the IRES (44). To confirm that stocks of PRV7.3 and $\mathrm{P} 3 /$ Sabin are free of such revertants, the proportion of $U$ at nucleotide 472 was determined by cleavage of a DNA copy of the IRES with MboI (Figure 7). According to a standard curve produced with plasmid DNA (data not shown), more than $99 \%$ of the viral RNA in stocks of PRV7.3 and P3/Sabin has a U at nucleotide 472 . Similarly, nearly $99 \%$ of the PRV7.3 or P3/Sabin viral RNA recovered from the brains of paralyzed mice has a $U$ at nucleotide 472 . When plasmid DNA that encodes a $\mathrm{C}$ at this position was assayed, cleavage of $100 \%$ of $\mathrm{MboI}$ sites was never observed, most likely because the DNA is damaged during PCR amplification (Figure 7, lane 2). However, the proportion of base $\mathrm{C}$ detected at nucleotide 472 in viral RNA from stocks of PRV8.4 and P3/119/70 and in RNA recovered from the brains of mice infected with these viruses was similar to that in plasmid DNA that encodes a $\mathrm{C}$ at this position. These findings show that paralysis in newborn mice inoculated with neuroattenuated viruses is not caused by a reversion of the C472U mutation.

In cell culture, the $C 472 \mathrm{U}$ mutation confers a temperature-sensitive phenotype that can be suppressed by mutations in the $2 \mathrm{~A}^{\text {pro }}$ coding region (45). Furthermore, mutation to A at IRES nucleotide 537 might restore neurovirulence by improving base pairing between nucleotides 472 and 537 (46). To ensure that the neurovirulence of PRV7.3 in newborn mice is not a consequence of suppressor mutations, the nucleotide sequence was determined in these regions of viral RNA from the brains of four paralyzed mice. No sequence changes were found in the $2 \mathrm{~A}^{\text {pro }}$ coding region. In viral RNA from two mice, the parental base, $G$, was found at nucleotide 537. In viral RNA from two other mice, a mixed population of the parental nucleotide 537G and the mutation 537A was found. These results indicate that mutations within the $2 \mathrm{Apro}$ coding region or at nucleotide 537 are not essential for neurovirulence.

Table 1

Virulence of poliovirus strains in TgPVR mice

\begin{tabular}{|c|c|c|c|c|c|}
\hline \multirow[b]{2}{*}{ Virus } & \multirow[b]{2}{*}{ Base 472} & \multicolumn{4}{|c|}{$\mathrm{LD}_{50}$ in mouse, PFUs } \\
\hline & & $\begin{array}{c}\text { TgPVR } \\
4 \text { weeks old }\end{array}$ & $\begin{array}{c}\text { TgPVR } \\
\text { 1-2 days old }\end{array}$ & $\begin{array}{c}\text { Non-Tg } \\
4 \text { weeks old }\end{array}$ & $\begin{array}{c}\text { Non-Tg } \\
1-2 \text { days old }\end{array}$ \\
\hline PRV7.3A & U & $>10^{8}$ & $1.3 \times 10^{4}$ & ND & ND \\
\hline PRV8.4A & C & $2.4 \times 10^{5}$ & $3.7 \times 10^{3}$ & ND & ND \\
\hline P3/Sabin & U & $>10^{8}$ & $6.2 \times 10^{4}$ & $>2 \times 10^{8}$ & $>5 \times 10^{7}$ \\
\hline P3/119/70 & C & $2.8 \times 10^{5}$ & $2 \times 10^{2}$ & $>10^{8}$ & $>3 \times 10^{7}$ \\
\hline
\end{tabular}

ARecombinant viruses comprising nucleotides 1-784 from P3/Sabin (PRV7.3) or P3/119 (PRV8.4) and the remainder of the genome from P2/Lansing (26). Human poliovirus receptor is not essential for infection of mice with P2/Lansing. ND, not determined. 
A

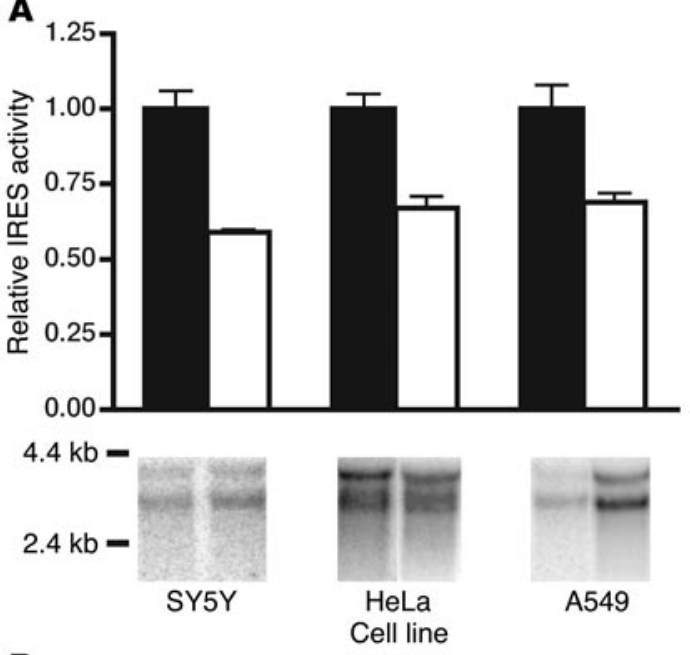

B

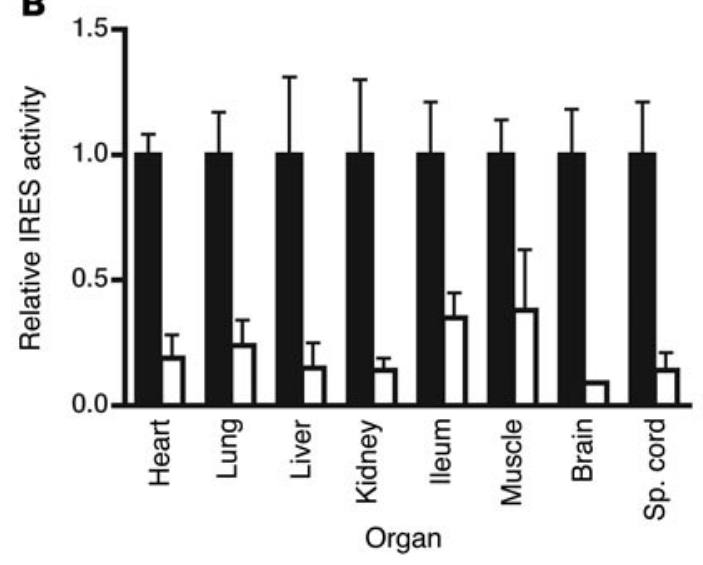

\section{Discussion}

Internal ribosome entry mediated by a cellular or viral IRES is commonly studied by monitoring the synthesis of IRES-dependent reporter proteins. The poliovirus IRES can also be modified in its normal location in an mRNA, the viral genome, and the effects on the viral-replication cycle can then be determined in infected cells or organs. This combination affords a unique approach to the study of translational control in mammalian tissues.

Although the poliovirus receptor is produced in a broad range of organs $(17,18)$, viral replication and disease are limited to a few sites, including the brain, spinal cord, and alimentary tract. It has been proposed that this restriction is established at the step of IRES-mediated translation of the viral RNA $(11-14,47)$. This

\section{Figure 7}

Base at nucleotide 472 in poliovirus recovered from paralyzed mice. Upper panel: Representative Southern blot hybridization of Mbol-cleaved PCR products. The 93-bp DNA (472U) and 61-bp DNA (472C) are indicated. Lower panel: Proportion of $472 \mathrm{U}$ in each sample, determined by quantitative analysis of Southern blots. For mouse brain, data points are the mean of at least three mice except for P3/Sabin, for which one mouse was analyzed. Error bars indicate SD. The $x$ axis indicates template for RT-PCR. Lane 1, plasmid DNA encoding P3/Sabin IRES; lane 2, plasmid DNA encoding P3/119/70 IRES; lanes 3-6, virus stocks used for infection of TgPVR mice; lanes 7-10, RNA from brain of TgPVR mice infected with the indicated virus stock.

\section{Figure 6}

Effect of $\mathrm{C} 472 \mathrm{U}$ mutation on translation of bicistronic mRNAs expressed by recombinant adenovirus. (A) Upper panel: Activity of P3/Sabin IRES (white bars) relative to P3/119/70 IRES (black bars) in SY5Y, HeLa, and A549 cells. Lower panel: Representative Northern blot hybridization of RNA from the same infected cells. (B) Activity of P3/Sabin IRES (white bars) relative to $\mathrm{P} 3 / 119 / 70$ IRES (black bars) in murine organs. Data points are the mean of three infections, and error bars indicate SD.

hypothesis cannot be tested in cell culture, because poliovirus replication occurs in cell lines derived from many organs that do not support viral replication (48). However, direct measurements of viral IRES-mediated translation in organs would address the question of whether IRES activity correlates with the sites of virus replication in the animal. Previous analyses of transgenic mice that express a bicistronic mRNA have demonstrated a lack of organ specificity in translation mediated by the IRES of encephalomyocarditis virus (49) and Theiler murine encephalomyelitis virus (50). In the present study, the use of recombinant adenoviral vectors permitted the analysis of the IRES from multiple viruses in a fraction of the time required for a transgenic approach. Contrary to expectations, the IRESs of $\mathrm{HCV}$, poliovirus, and CVB3 mediate translation in many murine organs, including those that are not sites of virus replication. Therefore, levels of IRES-dependent translation do not determine the organ-specific pattern of poliovirus replication. By expression of bicistronic mRNAs with adenovirus vectors, a pattern of IRES-mediated translation was revealed in organs that was not apparent in studies of cultured cells. It would therefore be of interest to use this approach to study the effect of different physiological states on cellular IRES-mediated translation.

Mouse models of human poliomyelitis may also provide insight into the relationship between poliovirus IRES-mediated translation and viral pathogenesis. Transgenic mice that produce the poliovirus receptor, CD155, are susceptible to poliovirus infection and develop disease that clinically and histopathologically resembles poliomyelitis $(40,51)$. Although

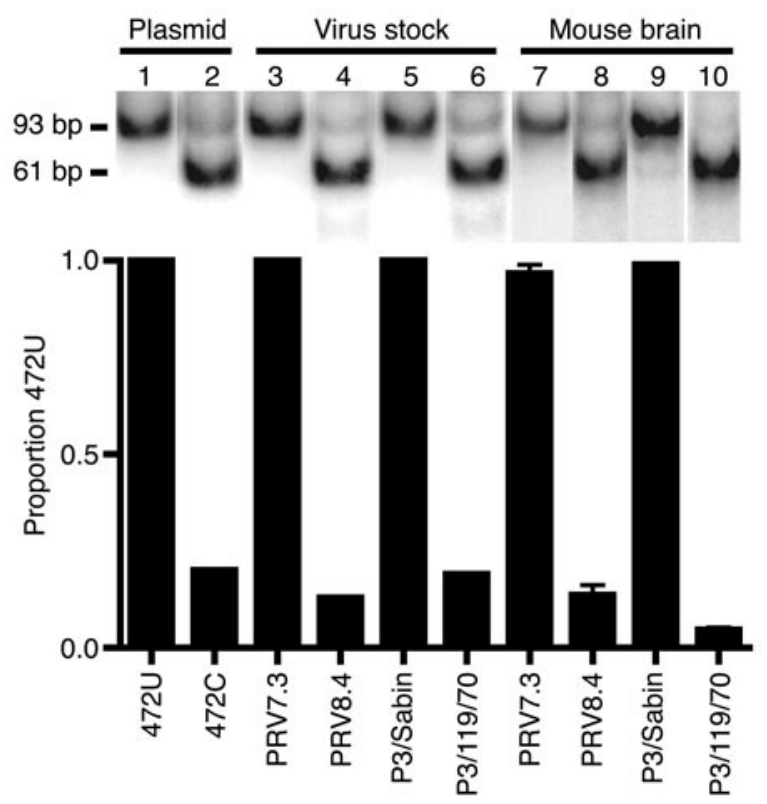




\section{Table 2}

Components of PCR reactions

\begin{tabular}{|c|c|c|c|}
\hline Template & 5'Primer & 3' Primer & PCR product \\
\hline $\begin{array}{l}\text { pGL3 promoter } \\
\text { (Promega Corp.) }\end{array}$ & 5'-CGCGAATTCATGGAAGACGCCAAAAAC-3' & $\begin{array}{l}\text { 5'-CGCAGATCTGCGGCCGCCTGCAGGATA } \\
\text { TCTTACACGGCGATCTTTCC-3' }\end{array}$ & Firefly luciferase \\
\hline $\begin{array}{l}\text { pRL-tk (Promega Corp.) } \\
\text { P3/119/70 subgenomic }\end{array}$ & 5'-CGCGAGCTCATGACTTCGAAAGTTTAT-3' & 5'-CGCGTCGACTTATTGTTCATTTTTGAG-3' & Renilla luciferase \\
\hline DNA clone & 5'-CGCCTGCAGTTAAAACAGCTCTGGGGT-3' & 5'-CGCGAGCTCTGTGACACTGAAATCCTG-3' & Poliovirus type 3 119/70 IRES \\
\hline $\begin{array}{l}\text { P3/Sabin subgenomic } \\
\text { DNA clone }\end{array}$ & 5'-CGCCTGCAGTTAAAACAGCTCTGGGGT-3' & 5'-CGCGAGCTCTGTGACACTGAAATCCTG-3' & Poliovirus type 3 Sabin IRES \\
\hline pT7-5'NCR-X472 (ref. 33) & 5'-CGCCTGCAGTTAAAACAGCTCTGGGGT-3' & 5'-CGCGAGCTCTATGATACAATTGTCTGA-3' & $\begin{array}{l}\text { Poliovirus type } 1 \\
\text { 5'NC-X472 IRES }\end{array}$ \\
\hline pC1b (ref. 64) & 5'-CGCCTGCAGCCGATTGGGGGCGACACT-3' & 5'-CGCGAGCTCAGGATTCGTGCTCATGAT-3' & HCV 1b IRES \\
\hline $\begin{array}{l}\text { pAR100 (A. Rosenfeld } \\
\text { and V. Racaniello, } \\
\text { unpublished data) }\end{array}$ & 5'-CGCCTGCAGCCGATTGGGGGCGACACT-3' & 5'-CGCGAGCTCAGGATTCGTGCTCATGAT-3' & HCV 1a IRES $\triangle 28-69$ \\
\hline pP1/CVB3 (see Methods) & 5'-CGCGTCGACTTAAAACAGCTCTGGGGT-3' & 5'-CGCGAGCTCTTTGCTGTATTCAACTTA-3' & CVB3 IRES \\
\hline
\end{tabular}

an excellent animal model for poliomyelitis, CD155 transgenic mice are not susceptible to poliovirus infection by the oral route, the natural means of infection in humans (52). We found that the tropism of recombinant polioviruses dependent on the IRES of CVB3 or HCV is unchanged in CD155 transgenic mice. These findings support the conclusion that a viral IRES can mediate translation in a wide range of organs and does not determine where poliovirus replicates and causes disease.

Previously, poliovirus dependent on the HCV IRES was reported to be cleared from the brain and spinal cord of adult mice without causing disease (13). These results led to the conclusion that the HCV IRES does not mediate translation initiation in the murine brain and spinal cord. An alternative explanation is that the recombinant virus replicates poorly (53) and is cleared by the immune system. We found that $\mathrm{P} 1 / \mathrm{HCV}$ is cleared from adult CD155 transgenic mice but replicates in the brain and spinal cord of newborn CD155 transgenic mice and causes flaccid paralysis. Newborn mice are more susceptible than adults to infection with neurotropic viruses, including poliovirus (54-56), but the basis for the increased susceptibility to poliovirus infection is not known. Taken together with the observation that the HCV IRES mediates translation in multiple organs, the finding that $\mathrm{P} 1 / \mathrm{HCV}$ replicates and causes paralysis in newborn mice indicates that the murine brain and spinal cord produce the proteins required for HCV IRES-dependent initiation.

A recombinant poliovirus dependent on the human rhinovirus 2 IRES is neuroattenuated in adult mice (12). A similar recombinant poliovirus is also neuroattenuated in newborn CD155 transgenic mice (data not shown). While the mechanism of attenuation is unclear, the HRV2 IRES may be dependent on cell proteins not present in the brain and spinal cord. This possibility is currently being explored.

Assertions that poliovirus tropism may be determined at the step of translation initiation (12-14) were in part based on previous studies of the mechanism of attenuation of the poliovirus live vaccine strains. The C472U mutation within the IRES of the Sabin type 3 vaccine strain attenuates neurovirulence (23) and was shown to cause a translation defect in vitro (28). The Sabin type 3 vaccine replicates poorly in a neuroblastoma cell line but not in HeLa cells, a phenotype attributed to the C472U mutation (30,
57). Poor replication in neuroblastoma cells was believed to be a consequence of reduced IRES-mediated translation (27). These observations led to the hypothesis that attenuating mutations in the Sabin vaccine IRES change poliovirus tropism by causing a translation defect specific to the brain and spinal cord $(27,30)$. To address this hypothesis, we measured IRES-mediated translation in organs and cells. Contrary to our expectation, the C472U mutation leads to identical translation defects in neuronal and non-neuronal organs and cells. This translation defect should lead to decreased viral replication in neuronal and non-neuronal organs. Our observation that the C472U mutation led to reduced IRES-mediated translation in all organs examined is consistent with the previous finding that this mutation reduces translational efficiency in extracts of non-neuronal cells (28). This observation is not consistent with previous conclusions that the effect of the $\mathrm{C} 472 \mathrm{U}$ mutation is specific for cells of neuronal origin and does not decrease viral translation or replication in HeLa cells $(27,30$, 57). In our study, variation in mRNA levels that could influence synthesis of the IRES-dependent reporter protein is controlled by the use of bicistronic mRNAs to quantify IRES-mediated translation. Furthermore, IRES-mediated translation might not be the rate-limiting step of viral replication in HeLa cells.

Mutations in the IRES are major determinants of the low pathogenicity of the poliovirus vaccine strains (22-24). The results reported here indicate that the $\mathrm{C} 472 \mathrm{U}$ attenuating mutation reduces IRES-dependent translation in all tissues, not only the CNS as previously hypothesized. Furthermore, we find that the C472U mutation does not eliminate viral replication in the CNS, since viruses with this mutation are neurovirulent in newborn mice. How might the C472 mutation reduce poliovirus neurovirulence in humans, yet still allow for sufficient virus replication to ensure protective immunity? Poliovirus infection of humans begins in the alimentary tract, and disease of the CNS is rare $(58,59)$. Replication defects in the alimentary tract associated with $\mathrm{C} 472 \mathrm{U}$ may decrease the probability that a sufficient number of virus particles will reach the brain and spinal cord to initiate a productive infection, without impairing the immunogenicity of the vaccine. Testing this hypothesis will require the development of a transgenic mouse that is susceptible to poliovirus infection by the oral route. 
Our results show that polioviruses with the $\mathrm{C} 472 \mathrm{U}$ mutation are neurovirulent in newborn but not adult mice. The basis for this difference in pathogenicity is not known. One possibility is that the immature immune system of the newborn mouse cannot effectively clear the virus infection, even though viral replication is compromised by the $\mathrm{C} 472 \mathrm{U}$ mutation. Our findings emphasize that attenuation of poliovirus neurovirulence is not simply a matter of whether or not IRES-mediated translation occurs in the brain and spinal cord. The outcome of infection is determined by a complex interplay between virus and host.

\section{Methods}

Cells, plasmids, and viruses. S3 HeLa and A549 cells were grown in DMEM (Invitrogen Corp., Carlsbad, California, USA), 10\% bovine calf serum (HyClone, Logan, Utah, USA), and 1\% penicillin/streptomycin (Invitrogen Corp.). SY5Y and 293 cells were grown in the same medium except that 10\% FBS (Invitrogen Corp.) was used. For plaque assays, HeLa cells were grown in DMEM (Specialty Media, Phillipsburg, New Jersey, USA), $0.2 \% \mathrm{NaHCO}_{3}, 5 \%$ bovine calf serum, $1 \%$ penicillin/streptomycin, and $0.9 \%$ bacto-agar (Difco Laboratories Inc., Franklin Lakes, New Jersey, USA).

A bicistronic expression plasmid encoding firefly luciferase and Renilla luciferase (Figure 1A) was created. A firefly luciferase PCR product was cleaved with EcoRI/BglII and ligated to EcoR/ BglII-cleaved pDC516 (Microbix Biosystems Inc., Toronto, Ontario, Canada). A Renilla luciferase PCR product was cleaved with SacI/SalI and ligated to a SacI/SalI cleavage of the above plasmid. PCR components are described in Table 2. The IRESs of poliovirus strains P3/119/70, P3/Sabin, and 5'NC-X472, HCV strain 1b, HCV strain 1a with nucleotides 28-69 deleted, and CVB3 were PCR-amplified with primers that add PstI and SacI sites to the $5^{\prime}$ and $3^{\prime}$ ends (Table 2) and ligated to PstI/SacIcleaved bicistronic expression plasmid.

Plasmid $\mathrm{pP} 1 / \mathrm{HCV}$, an infectious poliovirus DNA clone in which nucleotides 108-745 are replaced with HCV sequence, was created as follows. Plasmid pBSSK was prepared from pBluescript II SK+ (Stratagene, La Jolla, California, USA) by removal of SacI and $K p n I$ restriction sites and the T7 promoter. The T7 promoter and poliovirus nucleotides 1-107 were amplified by PCR from pT7M, a full-length clone of type 1 poliovirus strain Mahoney, with SK28 (5'-CGCGTCGACTAATACGACTCACTATAG-3') and SK29 (5'-CGCGAATTCAAGTTACGGGAAGGGAGT-3'), cleaved with SalI and EcoRI, and ligated to SalI/EcoRI-cleaved pBSSK. Nucleotides 746-1,127 of the poliovirus genome were amplified by PCR from pT7M with SK30 (5'-CGCGAATTCCGCGAGCTCAAAGGTCTCACAACATATGGTGCTCAGGTTTCATCA-3') and SK31 (5'-CGCGCGGCCGCGATATCAGCGACGTCTGGTTCTGT-3'), cleaved with EcoRI and NotI, and ligated to EcoRI/NotI-cleaved pBSSK. Nucleotides 1,119-7,440 of the poliovirus genome were isolated from AatII/SmaI-cleaved pT7M and ligated to AatII/EcoRV-cleaved pBSSK. The HCV IRES was amplified by PCR from pC1b, cleaved with EcoRI and SacI, and ligated to EcoRI/SacI-cleaved pBSSK.

Plasmid pP1/CVB3, an infectious poliovirus DNA clone in which nucleotides 108-742 are replaced with CVB3 sequence, was created as follows. Nucleotides 743-1,127 of the poliovirus genome were amplified by PCR from PT7M with SK31 and SK90 (5'-CGCGAGCTCATGGGTGCTCAGGTTTCA-3') cleaved with SacI and AatII, and used to replace the 373-bp SacI/AatII fragment from $\mathrm{pBSSK}$ at the point prior to insertion of $\mathrm{HCV}$ sequence.
The CVB3 IRES was amplified by PCR from pCVB3-28 (60) with SK91 (5'-CGCGAATTCCTTAGAAGTAACACACAC- ${ }^{\prime}$ ) and SK92 (5'-CGCGAGCTCTTTGCTGTATTCAACTTA-3'), cleaved with EcoRI and SacI, and ligated to EcoRI/SacI-digested pBSSK. The sequences of all PCR products were determined and verified to be consistent with published versions.

Recombinant human adenoviruses were produced using the AdMax system (Microbix Biosystems Inc.). Viruses encoding bicistronic mRNAs were created by recombination in 293 cells between calcium phosphate-transfected adenovirus genome plasmid $\mathrm{pBHGfrt} \Delta \mathrm{E} 1,3 \mathrm{FLP}$ and $\mathrm{pDC} 516$-based plasmids that encode bicistronic mRNAs. Recovered virus was subjected to two rounds of plaque purification as described by the manufacturer (Microbix Biosystems Inc.). Virus stocks were established by infection of 293 cells, and virus was purified from cells by centrifugation onto a cushion of cesium chloride as described by the manufacturer (Microbix Biosystems Inc.).

To produce poliovirus strains $\mathrm{P} 1 / \mathrm{M}, \mathrm{P} 1 / \mathrm{HCV}$, and $\mathrm{P} 1 / \mathrm{CVB} 3$, viral DNA clones $\mathrm{pT} 7 \mathrm{M}, \mathrm{pP} 1 / \mathrm{HCV}$, and $\mathrm{pP} 1 / \mathrm{CVB} 3$ were linearized by restriction enzyme cleavage and used as templates for run-off transcription by T7 RNA polymerase (Promega Corp., Madison, Wisconsin, USA). RNA was transfected into HeLa cells using DEAE-dextran, and after 3 days intracellular virus was released by three freeze-thaw cycles and passed once in HeLa cells. Virus was subjected to two rounds of plaque purification, and virus stocks were produced in HeLa cells. Poliovirus strains PRV7.3, PRV8.4, P3/Sabin, and P3/119/70 were produced by transfection of HeLa cells with viral DNA clones using DEAEdextran, and stocks were produced similarly. PRV7.3 and PRV8.4 are recombinant viruses comprising nucleotides $1-784$ from P3/Sabin (PRV7.3) or P3/119 (PRV8.4) and the remainder of the genome from P2/Lansing (26). Human poliovirus receptor is not essential for infection of mice with P2/Lansing.

Assay for IRES-dependent translation in continuous cell lines. Monolayers of adherent cells were infected at a multiplicity of 10 PFUs per cell with adenoviruses encoding bicistronic mRNAs. After 24 hours, medium was aspirated, monolayers were washed with $1 \mathrm{ml} \mathrm{PBS}$, and one-tenth of the cells were lysed in $1 \mathrm{ml}$ passive lysis buffer (PLB; Promega Corp.). For Northern blot hybridization of the same infection (see "Northern hybridization analysis" below), RNA was extracted from the remaining nine-tenths of infected cells. The Dual-Luciferase Assay (Promega Corp.) and the Lumat LB 9507 luminometer (Berthold Technologies GmbH $\&$ Co., Oak Ridge, Tennessee, USA) were used to determine firefly luciferase and Renilla luciferase activity in lysates. To control for variation in infection or transcription, the ratio of firefly luciferase activity to Renilla luciferase activity was determined (IRES activity). Unless otherwise indicated, to control for IRESindependent Renilla luciferase translation, the activity of each IRES was normalized to the ratio determined in lysates from cells infected with an adenovirus lacking an IRES. The concentration of luciferase protein was calculated with reference to a standard curve generated using known concentrations of recombinant firefly luciferase (Fisher Scientific Co., Springfield, New Jersey, USA) and Renilla luciferase (Chemicon International Inc., Temecula, California, USA).

Northern bybridization analysis. Monolayers of adherent cells were infected at a multiplicity of 10 PFUs per cell with adenoviruses encoding bicistronic mRNAs. After 24 hours, medium was aspirated and total RNA isolated with TRIzol (Invitrogen Corp.). Total 
RNA $(15 \mu \mathrm{g})$ was fractionated in a $1 \%$ agarose formaldehyde gel and transferred to GeneScreen membrane (PerkinElmer Analytical and Life Sciences, Boston, Massachusetts, USA) according to standard protocols (61). RNA was UV-crosslinked to the membrane (Stratalinker; Stratagene) and baked 2 hours at $80^{\circ} \mathrm{C}$ under a vacuum. Blots were hybridized with a PCR DNA product of the Renilla luciferase coding region labeled with ${ }^{32} \mathrm{P}-\mathrm{dCTP}$ by random priming (Rediprime; Amersham Biosciences, Piscataway, New Jersey, USA) according to standard protocols (62). For quantitation, a storage phosphor screen (Amersham Biosciences) was exposed to hybridized membranes for 1-6 days, scanned with the PhosphorImager 445SI (Molecular Dynamics), and analyzed with IQMac software (Molecular Dynamics).

Assay for IRES-dependent translation in murine organs. Four-weekold C57BL/6J mice (The Jackson Laboratory, Bar Harbor, Maine, USA) were injected intraperitoneally with $10^{9} \mathrm{PFUs} \mathrm{recombinant}$ human adenovirus for assays of heart, lung, liver, kidney, and ileum, intramuscularly with $5 \times 10^{8}$ PFUs for assays of muscle, and intracerebrally with $5 \times 10^{8}$ PFUs for assays of brain and spinal cord. The volume of all inoculations was $50 \mu \mathrm{l}$. Sixteen to 24 hours after infection, mice were sacrificed, and organs were removed and homogenized with a PowerGen 125 homogenizer (Fisher Scientific Co.) in $0.5 \mathrm{ml}$ PLB. Crude protein extracts were prepared, and the Dual-Luciferase Assay and the Lumat LB 9507 luminometer were used to determine firefly luciferase and Renilla luciferase activity in the extracts. To control for variation in infection or transcription, the ratio of firefly luciferase activity to Renilla luciferase activity was determined (IRES activity). To control for IRES-independent Renilla luciferase translation, the activity of each IRES was normalized to the ratio determined in organs from mice infected with an adenovirus lacking an IRES. All experimental mouse protocols adhered to Institutional Animal Care and Use Committee (IACUC) guidelines and were approved by the IACUC of Columbia University Medical Center (New York, New York, USA).

Poliovirus replication in HeLa cells. Monolayers of adherent HeLa cells were infected at a multiplicity of 10 PFUs per cell. At indicated time points, cells were scraped into tubes and subjected to three freeze-thaw cycles to release intracellular virus. The virus titer in each sample was determined by infection of HeLa cell monolayers and plaque assay.

Infection of TgPVR mice with poliovirus. TgPVR mice transgenic for the human poliovirus receptor (40) were genotyped to ensure that they carried the human poliovirus receptor gene. Mice lacking the pur gene were used as negative controls. Tail fragments were incubated overnight at $55^{\circ} \mathrm{C}$ in $0.2 \mathrm{ml}$ of $50 \mathrm{mM} \mathrm{KCl}, 10 \mathrm{mM}$ Tris (pH 8.3), $2.5 \mathrm{mM} \mathrm{MgCl}_{2}, 0.1 \mathrm{mg} / \mathrm{ml}$ gelatin, $0.45 \% \mathrm{NP} 40,0.45 \%$ Tween-20, and $60 \mu \mathrm{g}$ proteinase $\mathrm{K}$ (The Jackson Laboratory). Two microliters of the digestion product was used as template for PCR under standard conditions using 20A1C (5'-CTCACCACTGTACTCTAGTCTG-3') and 20A1W (5'-AGAAGGACTCACTAGACTCAGG-3'). The human poliovirus receptor gene was indicated by a 350-bp PCR product.

To assay viral replication, the following inoculations were performed. TgPVR mice (either 4 weeks old or 1-2 days old) were inoculated intraperitoneally with $10^{5}$ PFUs or $10^{3}$ PFUs of poliovirus type 1 strain Mahoney in a volume of $50 \mu \mathrm{l}$ or 15 $\mu 1$. TgPVR mice (4 weeks old) were inoculated with $10^{7}$ PFUs $\mathrm{P} 1 / \mathrm{CVB} 3$ in a volume of $50 \mu \mathrm{l}$. TgPVR mice (1-2 days old) were inoculated intraperitoneally with $10^{7} \mathrm{PFUs} \mathrm{P} 1 / \mathrm{HCV}$ in a volume of $15 \mu \mathrm{l}$. At the indicated time points, mice were sacrificed and organs were removed and homogenized with a PowerGen 125 homogenizer. Intracellular virus was released by three freezethaw cycles, and cellular debris was removed by centrifugation at $16,100 \mathrm{~g}$ for 15 minutes at $4^{\circ} \mathrm{C}$. The titer of infectious virus in the supernatant of each sample was determined by infection of HeLa cell monolayers and plaque assay. To determine survival of infected mice, 15 TgPVR mice were inoculated with P1/CVB3 and 27 TgPVR mice were inoculated with $\mathrm{P} 1 / \mathrm{HCV}$ as described above. Nine TgPVR mice were also inoculated with $10^{9}$ PFUs P1/HCV. Mice were observed daily for paralysis or death, and paralyzed mice were sacrificed immediately.

Neurovirulence assays. TgPVR mice were genotyped as described above, and mice were inoculated intracerebrally with tenfold serial dilutions of virus. Mice 1-2 days old were inoculated with $15 \mu \mathrm{l}$, and mice 4 weeks old were inoculated with $50 \mu$ l. Between 7 and 11 mice were inoculated with each dilution of virus. Mice were observed daily for paralysis or death, and paralyzed mice were sacrificed immediately. The $50 \%$ lethal dose $\left(\mathrm{LD}_{50}\right)$ value for each virus was calculated according to the number of dead and paralyzed mice at each dilution, following the method of Reed and Muench (63).

Nucleotide sequence of poliovirus $R N A$ recovered from paralyzed $T g P V R$ mice. Viral RNA was extracted from the brains of paralyzed mice as follows. TgPVR mice 1-2 days old were inoculated intracerebrally with $10^{5}$ PFUs PRV7.3, $5 \times 10^{6}$ PFUs P3/Sabin, $10^{4}$ PFUs PRV8.4, or $3 \times 10^{3}$ PFUs P3/119/70. Upon onset of paralysis $10,7,6$, or 6 days after infection, respectively, mice were sacrificed and brains removed. Brains were homogenized in $1 \mathrm{ml}$ PBS with $0.2 \%$ bovine calf serum and subjected to three freeze-thaw cycles to release intracellular virus. Cellular debris was removed by centrifugation at $16,100 \mathrm{~g}$ for 15 minutes at $4^{\circ} \mathrm{C}$. Total RNA was extracted from $0.2 \mathrm{ml}$ of supernatant with $1 \mathrm{ml}$ TRIzol. RNA was also extracted directly from virus stocks to confirm the sequence at nucleotide 472.

The base at nucleotide 472 in viral RNA was determined by RTPCR and restriction enzyme cleavage as previously described (44). First-strand cDNA was produced with $5 \mu \mathrm{g}$ of total RNA using the ImProm-II reverse transcription system (Promega Corp.) and primer SK77 (5'-ACGGACTTGCGCGTTACGACAGGCTGGCTGC-3'). Five microliters of the reaction mixture was used in a PCR amplification with SK76 (5'-TGAGAGTCCTCCGGCCCCTGAATGCGGCTGAT-3') and SK77. Approximately $0.4 \mu \mathrm{g}$ plasmid pSK48 or pSK49 was used as PCR template in control reactions. PCR produces a 93-bp product, and the base $\mathrm{C}$ at nucleotide 472 creates an $M b o$ I restriction endonuclease site. This is cleaved to produce 61-bp and 32-bp products. Cleavage of $100 \%$ of $\mathrm{MboI}$ sites was never observed, most likely because of DNA damage during PCR amplification (Figure 7, lane 2). After incubation with $\mathrm{MboI}$ and electrophoresis in 10\% acrylamide, DNA was transferred (Trans-Blot; Bio-Rad Laboratories Inc., Hercules, California, USA) to GeneScreen membrane. Blots were hybridized according to standard protocols (62) with the product of PCR amplification of pSK49 with SK76 and SK77 labeled with ${ }^{32} \mathrm{P}-\mathrm{dCTP}$ by random priming. For quantitation, a storage phosphor screen was exposed to hybridized membranes for approximately 12 hours, scanned with the PhosphorImager 445SI, and analyzed with IQMac software. The proportion of $472 \mathrm{U}$ was calculated as the ratio of $93-\mathrm{bp}$ DNA density to the sum of the 93-bp, 61-bp, and 32-bp DNA densities, according to a standard curve generated with plasmid DNA encoding the poliovirus IRES with $472 \mathrm{U}$ or $472 \mathrm{C}$. The standard curve was linear from a proportion of $1-100 \%$ C at 472. 
To determine the nucleotide sequence of the IRES in viral RNA recovered from paralyzed mice infected with PRV7.3, first-strand cDNA was produced with primer SK88 (5'-CGCGAGCTCTGTGACACTGAAATCCTG- $3^{\prime}$ ) and used in a PCR amplification with SK88 and SK103 (5'-ATAGCGGCCGCTTAAAACAGCTCTGGGGTTG-3') as described above. To determine the nucleotide sequence of the $2 \mathrm{~A}^{\text {pro }}$ coding region of viral RNA recovered from paralyzed mice infected with PRV7.3, first-strand cDNA was produced with primer SK107 (5'-GCGGCGGCCGCTTTGCTGGGTGAATCCAC-3') and used in a PCR amplification with SK107 and SK106 (5'-CGCCTGCAGTCCCATACTACGGACCAG-3') as described above. Nucleotide sequence of PCR products was determined by the Herbert Irving Comprehensive Cancer Center DNA Facility, Columbia University Medical Center.

\section{Acknowledgments}

We thank C.S.H. Young for technical advice and critical thought, and Jeff Almond, Akio Nomoto, Bert Semler, Steve Tracy, and Nora Chapman for plasmids. This work was supported by NIH grants R01 AI20017 and T32 AI07161.

Received for publication February 12, 2004, and accepted in revised form April 2, 2004.

Address correspondence to: Vincent R. Racaniello, Department of Microbiology, Columbia University College of Physicians and Surgeons, 701 W. 168th Street, New York, New York 10032, USA. Phone: (212) 305-5707; Fax: (212) 305-5106; E-mail: vrr1@columbia.edu.
1. Kozak, M. 1979. Inability of circular mRNA to attach to eukaryotic ribosomes. Nature. 280:82-85.

2. Both, G.W., Furuichi, Y., Muthukrishnan, S., and Shatkin, A.J. 1975. Ribosome binding to reovirus mRNA in protein synthesis requires $5^{\prime}$ terminal 7-methylguanosine. Cell. 6:185-195.

3. Jang, S.K., et al. 1988. A segment of the 5 ' nontranslated region of encephalomyocarditis virus RNA directs internal entry of ribosomes during in vitro translation. J. Virol. 62:2636-2643.

4. Holcik, M., Sonenberg, N., and Korneluk, R.G. 2000. Internal ribosome initiation of translation and the control of cell death. Trends Genet. 16:469-473.

5. Belsham, G.J., and Sonenberg, N. 1996. RNA-protein interactions in regulation of picornavirus RNA translation. Microbiol. Rev. 60:499-511.

6. Brasey, A., et al. 2003. The leader of human immunodeficiency virus type 1 genomic RNA harbors an internal ribosome entry segment that is active during the G2/M phase of the cell cycle. J. Virol. 77:3939-3949.

7. Hellen, C.U., and Sarnow, P. 2001. Internal ribosome entry sites in eukaryotic mRNA molecules. Genes Dev. 15:1593-1612.

8. Pelletier, J., Kaplan, G., Racaniello, V.R., and Sonenberg, N. 1988. Cap-independent translation of poliovirus mRNA is conferred by sequence elements within the $5^{\prime}$ noncoding region. Mol. Cell. Biol. 8:1103-1112.

9. Hewlett, M.J., Rose, J.K., and Baltimore, D. 1976. 5 '-Terminal structure of poliovirus polyribosomal RNA is pUp. Proc. Natl. Acad. Sci. U. S. A 73:327-330.

10. Nomoto, A., Lee, Y.F., and Wimmer, E. 1976. The $5^{\prime}$ end of poliovirus mRNA is not capped with m7G(5')ppp(5')Np. Proc. Natl. Acad. Sci. U. S. A. 73:375-380.

11. Ohka, S., and Nomoto, A. 2001. The molecular basis of poliovirus neurovirulence. Dev. Biol. (Basel). 105:51-58.

12. Gromeier, M., Alexander, L., and Wimmer, E. 1996. Internal ribosomal entry site substitution eliminates neurovirulence in intergeneric poliovirus recombinants. Proc. Natl. Acad. Sci. U. S. A. 93:2370-2375.

13. Yanagiya, A., et al. 2003. Tissue-specific replicating capacity of a chimeric poliovirus that carries the internal ribosome entry site of hepatitis $\mathrm{C}$ virus in a new mouse model transgenic for the human poliovirus receptor. J. Virol. 77:10479-10487.

14. Borman, A.M., Le Mercier, P., Girard, M., and Kean, K.M. 1997. Comparison of picornaviral IRES-driven internal initiation of translation in cultured cells of different origins. Nucleic Acids Res. 25:925-932.

15. Bodian, D.M. 1959. Poliomyelitis: pathogenesis and histopathology. In Viral and rickettsial infections of man. T.M. Rivers and F.L. Horsfall, editors. J.B. Lippincott Co. Philadelphia, Pennsylvania, USA. 479-498.
16. Mendelsohn, C.L., Wimmer, E., and Racaniello, V.R. 1989. Cellular receptor for poliovirus: molecular cloning, nucleotide sequence, and expression of a new member of the immunoglobulin superfamily. Cell. 56:855-865.

17. Freistadt, M.S., Kaplan, G., and Racaniello, V.R. 1990. Heterogeneous expression of poliovirus receptor-related proteins in human cells and tissues. Mol. Cell. Biol. 10:5700-5706.

18. Ren, R., and Racaniello, V.R. 1992. Human poliovirus receptor gene expression and poliovirus tissue tropism in transgenic mice. J. Virol. 66:296-304.

19. Belsham, G.J., and Sonenberg, N. 2000. Picornavirus RNA translation: roles for cellular proteins. Trends Microbiol. 8:330-335.

20. Lu, H.H., and Wimmer, E. 1996. Poliovirus chimeras replicating under the translational control of genetic elements of hepatitis $\mathrm{C}$ virus reveal unusual properties of the internal ribosomal entry site of hepatitis C virus. Proc. Natl. Acad. Sci. U. S. A. 93:1412-1417.

21. Sabin, A.B., Hennessen, W.A., and Winsser, J. 1954. Studies on variants of poliomyelitis virus. J. Exp. Med. 99:551-576.

22. Kawamura, N., et al. 1989. Determinants in the 5 ' noncoding region of poliovirus Sabin 1 RNA that influence the attenuation phenotype. J. Virol. 63:1302-1309.

23. Evans, D.M., et al. 1985. Increased neurovirulence associated with a single nucleotide change in a noncoding region of the Sabin type 3 poliovaccine genome. Nature. 314:548-550.

24. Ren, R.B., Moss, E.G., and Racaniello, V.R. 1991. Identification of two determinants that attenuate vaccine-related type 2 poliovirus. J. Virol. 65:1377-1382.

25. Westrop, G.D., et al. 1989. Genetic basis of attenuation of the Sabin type 3 oral poliovirus vaccine. J. Virol. 63:1338-1344.

26. La Monica, N., Almond, J.W., and Racaniello, V.R. 1987. A mouse model for poliovirus neurovirulence identifies mutations that attenuate the virus for humans. J. Virol. 61:2917-2920.

27. Gutierrez, A.L., Denova-Ocampo, M., Racaniello, V.R., and del Angel, R.M. 1997. Attenuating mutations in the poliovirus 5 ' untranslated region alter its interaction with polypyrimidine tract-binding protein. J. Virol. 71:3826-3833.

28. Svitkin, Y.V., Cammack, N., Minor, P.D., and Almond, J.W. 1990. Translation deficiency of the Sabin type 3 poliovirus genome: association with an attenuating mutation C472----U. Virology. 175:103-109.

29. Haller, A.A., Stewart, S.R., and Semler, B.L. 1996. Attenuation stem-loop lesions in the 5 ' noncoding region of poliovirus RNA: neuronal cell-specific translation defects. J. Virol. 70:1467-1474.

30. La Monica, N., and Racaniello, V.R. 1989. Differences in replication of attenuated and neuroviru- lent polioviruses in human neuroblastoma cell line SH-SY5Y. J. Virol. 63:2357-2360.

31. Wang, C., Sarnow, P., and Siddiqui, A. 1993. Translation of human hepatitis C virus RNA in cultured cells is mediated by an internal ribosome-binding mechanism. J. Virol. 67:3338-3344.

32. Yang, D., et al. 1997. In vitro mutational and inhibitory analysis of the cis-acting translational elements within the $5^{\prime}$ untranslated region of coxsackievirus B3: potential targets for antiviral action of antisense oligomers. Virology. 228:63-73.

33. Haller, A.A., and Semler, B.L. 1992. Linker scanning mutagenesis of the internal ribosome entry site of poliovirus RNA. J. Virol. 66:5075-5086.

34. Honda, M., et al. 1996. Structural requirements for initiation of translation by internal ribosome entry within genome-length hepatitis $C$ virus RNA. Virology. 222:31-42.

35. Addison, C.L., Hitt, M., Kunsken, D., and Graham, F.L. 1997. Comparison of the human versus murine cytomegalovirus immediate early gene promoters for transgene expression by adenoviral vectors. J. Gen. Virol. 78:1653-1661.

36. Hoofnagle, J.H. 1997. Hepatitis C: the clinical spectrum of disease. Hepatology. 26(Suppl. 1):15S-20S.

37. Kandolf, R., et al. 1993. Molecular mechanisms in the pathogenesis of enteroviral heart disease: acute and persistent infections. Clin. Immunol. Immunopathol. 68:153-158.

38. Shiroki, K., et al. 1995. A new cis-acting element for RNA replication within the 5 ' noncoding region of poliovirus type 1 RNA. J. Virol. 69:6825-6832.

39. Borman, A.M., Deliat, F.G., and Kean, K.M. 1994. Sequences within the poliovirus internal ribosome entry segment control viral RNA synthesis. EMBOJ. 13:3149-3157.

40. Ren, R.B., Costantini, F., Gorgacz, E.J., Lee, J.J., and Racaniello, V.R. 1990. Transgenic mice expressing a human poliovirus receptor: a new model for poliomyelitis. Cell. 63:353-362.

41. Khatib, R., Chason, J.L., Silberberg, B.K., and Lerner, A.M. 1980. Age-dependent pathogenicity of group B coxsackieviruses in Swiss-Webster mice: infectivity for myocardium and pancreas. J. Infect. Dis. 141:394-403.

42. Tracy, S., et al. 2000. Group B coxsackievirus myocarditis and pancreatitis: connection between viral virulence phenotypes in mice. J. Med. Virol. 62:70-81.

43. Dorsam, V., et al. 2000. Increased safety level of serotype 3 Sabin oral poliomyelitis vaccine lots by improved seed virus, and tissue culture and virus infection conditions. Vaccine. 18:2435-2443.

44. Chumakov, K.M., Powers, L.B., Noonan, K.E., Roninson, I.B., and Levenbook, I.S. 1991. Correlation between amount of virus with altered nucleotide sequence and the monkey test for acceptability of oral poliovirus vaccine. Proc. Natl. Acad. Sci. U. S. A. 88:199-203. 
45. Macadam, A.J., et al. 1994. Role for poliovirus protease $2 \mathrm{~A}$ in cap independent translation. $E M B O$ J. 13:924-927.

46. Skinner, M.A., et al. 1989. New model for the secondary structure of the $5^{\prime}$ non-coding RNA of poliovirus is supported by biochemical and genetic data that also show that RNA secondary structure is important in neurovirulence. J. Mol. Biol. 207:379-392.

47. del Angel, R.M., Papavassiliou, A.G., FernandezTomas, C., Silverstein, S.J., and Racaniello, V.R. 1989. Cell proteins bind to multiple sites within the 5' untranslated region of poliovirus RNA. Proc. Natl. Acad. Sci. U. S. A. 86:8299-8303.

48. Enders, J.F., Weller, T.H., and Robbins, F.C. 1949. Cultivation of the Lansing strain of poliomyelitis virus in cultures of various human embryonic tissues. Science. 109:85-87.

49. Creancier, L., Morello, D., Mercier, P., and Prats, A.C. 2000. Fibroblast growth factor 2 internal ribosome entry site (IRES) activity ex vivo and in transgenic mice reveals a stringent tissue-specific regulation. J. Cell Biol. 150:275-281.

50. Shaw-Jackson, C., and Michiels, T. 1999. Absence of internal ribosome entry site-mediated tissue specificity in the translation of a bicistronic transgene. J. Virol. 73:2729-2738.

51. Koike, S., et al. 1991. Transgenic mice suscep- tible to poliovirus. Proc. Natl. Acad. Sci. U. S. A. 88:951-955.

52. Zhang, S., and Racaniello, V.R. 1997. Expression of the poliovirus receptor in intestinal epithelial cells is not sufficient to permit poliovirus replication in the mouse gut. J. Virol. 71:4915-4920.

53. Zhao, W.D., Wimmer, E., and Lahser, F.C. 1999 Poliovirus/Hepatitis C virus (internal ribosomal entry site-core) chimeric viruses: improved growth properties through modification of a proteolytic cleavage site and requirement for core RNA sequences but not for core-related polypeptides. J. Virol. 73:1546-1554.

54. Lewis, J., Wesselingh, S.L., Griffin, D.E., and Hardwick, J.M. 1996. Alphavirus-induced apoptosis in mouse brains correlates with neurovirulence. J. Virol. 70:1828-1835.

55. Lawrence, D.M., Vaughn, M.M., Belman, A.R., Cole, J.S., and Rall, G.F. 1999. Immune response-mediated protection of adult but not neonatal mice from neuron-restricted measles virus infection and central nervous system disease. J. Virol. 73:1795-1801.

56. Crotty, S., Hix, L., Sigal, L.J., and Andino, R. 2002. Poliovirus pathogenesis in a new poliovirus receptor transgenic mouse model: age-dependent paralysis and a mucosal route of infection. J. Gen. Virol. 83:1707-1720.

57. Agol, V.I., et al. 1989. Restricted growth of attenu- ated poliovirus strains in cultured cells of a human neuroblastoma. J. Virol. 63:4034-4038.

58. Wimmer, E., Hellen, C.U., and Cao, X. 1993. Genetics of poliovirus. Annu. Rev. Genet. 27:353-436.

59. Minor, P.D. 1997. Poliovirus. In Viral pathogenesis. N. Nathanson, editor. Lippincott Williams \& Wilkins - Raven Press. Philadelphia, Pennsylvania, USA. 555-574.

60. Tracy, S., Chapman, N.M., and Tu, Z. 1992 Coxsackievirus B3 from an infectious cDNA copy of the genome is cardiovirulent in mice. Arch. Virol. 122:399-409.

61. Ausubel, F.M., et al., editors. 1987. Current protocols in molecular biology. John Wiley \& Sons Inc. Hoboken, New Jersey, USA. 4.9.1-4.9.4.

62. Sambrook, J., Russell, D.W., Irwin, N., and Janssen, K.A. 2001. Molecular cloning: a laboratory manual. Cold Spring Harbor Laboratory Press. Cold Spring Harbor, New York, USA. 9.4-9.8.

63. Reed, L.J., and Muench, H. 1938. A simple method of estimating fifty percent endpoints. Am. J. Hyg. 27:493-497.

64. Kamoshita, N., Tsukiyama-Kohara, K., Kohara, M. and Nomoto, A. 1997. Genetic analysis of internal ribosomal entry site on hepatitis C virus RNA: implication for involvement of the highly ordered structure and cell type-specific transacting factors. Virology. 233:9-18. 